\title{
Changes in Circadian Rhythm due to Possibly Sympathetic Nerve Disorders in Patients with Preeclampsia as Assessed by Ambulatory Blood Pressure Monitoring
}

Tamao Yamamoto ${ }^{1}$, Yoshikatsu Suzuki ${ }^{1 *}$, Hiroki Suzuki ${ }^{1}$, Ayano Matsuura ${ }^{2}$, Hiroshi Matsushita ${ }^{1}$, Kazushi Watanabe ${ }^{1}$ and Akihiko Wakatsuki ${ }^{1}$ Department of Obstetrics and Gynecology, Aichi Medical University School of Medicine, Nagakuta, Japan

${ }^{2}$ Department of Obstetrics and Gynecology, Nagoya City West Medical Center, Nagoya, Japan

\section{Abstract}

Objectives: Women with hypertensive disorders of pregnancy (HDP), including both preeclampsia (PE) and gestational hypertension $(\mathrm{GH})$, show fluctuations in BP during the day. This study aimed to assess characteristic changes in BP by Ambulatory blood pressure (BP) monitoring (ABPM) in HDP patients in comparison with PE and $\mathrm{GH}$.

Study design: Among the 106 pregnant women who exhibited hypertension by clinic BP (CBP), 24-hour ABPM were performed. ABPM determined HDP in 79 women $(P E, n=43)$ and $\mathrm{GH}, \mathrm{n}=36)$, and white coat hypertension $(\mathrm{WCH})$ in 27 women.

Main outcome measures: The following aspects were analyzed with the circadian rhythms of BP and pulse: 1) changes in BP at night-time and 2) multiple regression percent rhythm (PR, correction coefficient by Cosinor analysis).

Results: Mean BP by 24-hour ABPM was higher in women with PE and GH compared to those with WCH. In systolic $\mathrm{BP}$ (SBP), most women with PE and GH were riser or non-dipper. Half of the women with PE and GH experienced a loss of circadian rhythm of SBP $(P R<0.16)$. In women with circadian rhythm $(P R \geq 0.16)$, normal maximal SBP at daytime (acrophase time from 12:00 to 18:00) was observed in only 9 of 43 women with PE and 9 of 36 women with $\mathrm{GH}$. Furthermore, PR of pulse was lower in women with PE, but not in those with $\mathrm{GH}$ or WCH.

Conclusions: Our findings suggest that the circadian rhythm of BP in women with PE may be abnormal due to possibly sympathetic nerve disorders.

Keywords: Preeclampsia; White Coat Hypertension; Circadian Rhythm; ABPM

\section{Introduction}

Blood pressure (BP) assessments in pregnant women have traditionally relied on measurements taken in the clinical setting (i.e., clinic BP (CBP)). Ambulatory BP monitoring (ABPM) with a reliable and accurate device is a logical alternative and provides the advantage of absolute BP values, as well as allowing for the analysis of circadian rhythm variations of $B P$ in pregnant women $[1,2]$. ABPM, as well as home BP measurement (HBPM), may replace or augment CBP in the diagnosis of hypertension.

The Best Practice Guide 2015 for Care and Treatment of Hypertension in Pregnancy set forth by the Japan Society for the Study of Hypertension in Pregnancy (JSSHP) states that there are two environments for measuring BP: under medical settings and nonmedical settings (e.g., HBPM and ABPM). 24-hour ABPM can be used to diagnose white coat hypertension $(\mathrm{WCH})$ and masked hypertension, as well as assess the efficiency of anti-hypertensive drugs and circadian variations in $\mathrm{BP}[3]$.

Moreover, ABPM has been used previously to predict hypertensive disorders of pregnancy (HDP), in particular, PE [4,5]. It can also be used as a strong predictor of adverse outcomes of pregnancy, such as preterm delivery and fetal growth restriction (FGR) $[6,7]$.

Hypertensive disorders of pregnancy (HDP) is defined as BP $\geq 140 / 90 \mathrm{mmHg}$, with or without proteinuria ( $\geq 300 \mathrm{mg} / 24 \mathrm{~h}$ ), emerging after 20 weeks gestation, but resolving by up to 12 weeks postpartum $[8,9]$. It is mainly classified as preeclampsia (PE) or gestational hypertension $(\mathrm{GH})$. GH is diagnosed in women who have hypertension without proteinuria, and conversely, $\mathrm{PE}$ is diagnosed when hypertension is accompanied by proteinuria. There are well-characterized differences between the pathogenesis and management of the two disorders.

The circadian rhythms of BP and pulse are obtainable by ABPM. BP is typically higher during the daytime and lower at night in response to the internal clock and mental and physical activities. In contrast to BP in the daytime (daytime BP), it is normal to see a drop in BP of more than $10 \%$ at night (night-time BP) in normotensive pregnant women. Most women with severe $\mathrm{PE}$ have an attenuated decrease in night-time BP $(<10 \%$; non-dipper) or exhibit increases in night-time BP (riser) $[10,11]$.

Cosinor analysis allows for the evaluation of BP variability in HDP and is calculated using MESOR (mean or midline estimating statistic of rhythms, average value of the rhythmic function fitted to the data), amplitude (Amp, one half the extent of change explainable by the rhythmic fitted curve), and acrophase time (AT, crest time expressed as a lag from a designated reference) in HDP. Amp and MESOR are reportedly larger in women with $\mathrm{PE}$ compared to normotensive

*Corresponding author: Dr. Y Suzuki, Department of Obstetrics and Gynecology Aichi Medical University School of Medicine, 1-1 Yazako Karimata, Nagakute, 480 1195, Japan, Tel: +81-561-62-3311; Fax: +81-561-62-2991; E-mail: ogyo 537@ hotmail.com

Received May 31, 2018; Accepted June 08, 2018; Published June 16, 2018

Citation: Yamamoto T, Suzuki Y, Suzuki H, Matsuura A, Matsushita H, et al. (2018) Changes in Circadian Rhythm due to Possibly Sympathetic Nerve Disorders in Patients with Preeclampsia as Assessed by Ambulatory Blood Pressure Monitoring. J Hypertens (Los Angel) 7: 250. doi: 10.4172/2167-1095.1000250

Copyright: @ 2018 Yamamoto T, et al. This is an open-access article distributed under the terms of the Creative Commons Attribution License, which permits unrestricted use, distribution, and reproduction in any medium, provided the original author and source are credited. 
Citation: Yamamoto T, Suzuki Y, Suzuki H, Matsuura A, Matsushita H, et al. (2018) Changes in Circadian Rhythm due to Possibly Sympathetic Nerve Disorders in Patients with Preeclampsia as Assessed by Ambulatory Blood Pressure Monitoring. J Hypertens (Los Angel) 7: 250. doi: 10.4172/2167-1095.1000250

Page 2 of 6

pregnant women [4].

Percent of coefficient variability (\%CV), which is calculated using the formula standard deviation (SD)/mean $\mathrm{x} 100$, and differences between maximum $\mathrm{BP}$ and minimum $\mathrm{BP}(\triangle \mathrm{BP})$, are also indicators of BP variability. Some pathological states reportedly exhibit increased $\% \mathrm{CV}$ and $\triangle \mathrm{BP}[12]$

Moreover, percent rhythm (PR), which is the square of the correlation coefficient by Cosinor analysis, is typically used to assess circadian rhythm by fitting data. However, PR has not been used to evaluate circadian rhythm in the context of HDP, given its unsuitability for analyzing HDP [4].

Changes in pulse are known to reflect potential dysfunction of the sympathetic system in certain pathological states. Indeed, pulse variation might be observed in women with HDP due to the influence of pathological changes. Furthermore, night-time hypertensive patients have a lower awake heart rate and heart rate variability than night-time normotensive patients [13-15].

For this backdrop, the present study aimed to assess characteristic changes in circadian rhythms of BP and pulse using 24-hour ABPM in pregnant women with $\mathrm{PE}$ and $\mathrm{GH}$ who were diagnosed with hypertension by CBP.

\section{Methods}

In this study, pregnant women who had SBP $\geq 140 \mathrm{mmHg}$ and/or DBP $\geq 90 \mathrm{mmHg}$ during pregnancy, as assessed by CBP, underwent 24-hour ABPM at Nagoya City West Medical center between 2014 and 2015 and at Aichi Medical University Hospital between 2015 and 2018. CBP, defined as BP measured in the outpatient clinic, was measured at least twice on two separate occasions after at least five minutes of rest in the sitting position. When all-day ABPM revealed an SBP $\geq 130 \mathrm{mmHg}$ and/or DBP $\geq 80 \mathrm{mmHg}$, patients were classified as having a hypertensive disorder (HDP), whereas patients with both $\mathrm{SBP}<130 \mathrm{mmHg}$ and $\mathrm{DBP}<80 \mathrm{mmHg}$ were classified as having $\mathrm{WCH}$ [1]. Exclusion criteria were as follows: a history of hypertension (not HDP), type 1 diabetes, renal dysfunction, hepatic damage, ischemic heart disease or other cardiac diseases, congestive heart failure (serum creatinine $41.2 \mathrm{mg} / \mathrm{dL}$ ), arrhythmias, stroke, or other major concomitant non-cardiovascular diseases.

Age, parity, and body mass index (BMI) before pregnancy, gestational weeks of delivery, and infant body weight were evaluated. FGR was diagnosed according to Japanese fetal growth standards [16]. Soluble flm-like growth factor 1 (sFlt-1) in serum was measured as a biomarker of HDP using a sFlt-1 ELISA kit (R \& D Systems, Inc, USA).

\section{ABPM}

Noninvasive ABPM was performed during pregnancy with an automatic validated system (TM-2430; A \& D, Tokyo) that records BP by the oscillometric method and pulse rate every $30 \mathrm{~min}$ for 24 hours [17,18]. Awake (daytime) and sleep (night-time) times were defined based on written diaries recorded during ABPM. A minimum of six valid awake readings and four valid sleep readings were required for the computation of daytime and night-time averages, but all participants had more than the required number of valid readings. Mean daytime, night-time, and 24-hour SBP, DBP, and pulse rate were computed. Since no normal reference values exist for pregnant women, we used standard reference values for the hypertensive population $[17,18]$.

\section{Circadian rhythm}

Data for SBP, DBP, and pulse were stored in BP analysis software (TM-2500; Doctor Pro3, A \& D Co., Ltd., Tokyo). These BP data were synchronized according to the sleep-wake cycle and analyzed [19]. The circadian BP pattern was classified as a riser pattern if the mean night-time $\mathrm{BP}$ exceeded the mean daytime $\mathrm{BP}$, and a non-riser pattern if the mean night-time $\mathrm{BP}$ was equal to or lower than the mean daytime BP $[4,5,11,20]$. The non-riser group consisted of both non-dipper (nocturnal BP fall $>0 \%$ but $<10 \%$ ) and dipper (nocturnal BP fall $>10 \%$ ).

Another circadian BP pattern was assessed by Cosinor analysis. The regression model for a single component can be expressed as $\mathrm{Y}=\mathrm{M}+\mathrm{Amp} \mathrm{X} \operatorname{Cos}(\mathrm{T}+\phi)$, where $\mathrm{M}$ is the MESOR (circadian rhythmadjusted mean based on parameters of a cosine function fitted to the raw data), Amp is the amplitude (amplitude of a cosine curve best fitted to the biological rhythm data), and $\phi$ is the acrophase (phase that represents the maximum value of a cosine curve best fitted to the biological rhythm data). Percent of coefficient variability (\%CV), an indicator of BP variability, was calculated as standard deviation (SD)/ mean $x$ 100. Percent rhythm (PR) was calculated as the square of the multiple correlation coefficients $\left(\mathrm{R}^{2}\right)$ between the measured value and the cosine curve best fitted to the biological rhythm data.

Patients were divided into two groups, i.e., those with circadian rhythm $(\mathrm{PR} \geq 0.16)$ and those without circadian rhythm $(\mathrm{PR}<0.16)$ The patients with circadian rhythm were divided into four categories by acrophase time (AT) as follows: AT0-6 (AT set at 0:00-6:00; reverse type), AT6-12 (AT set at 6:00-12:00), AT12-18 (AT set at 12:00-18:00 normal type), and AT18-24 (AT set at 18:00-24:00). In 36 patients, $\mathrm{ABPM}$ was also performed at postpartum three months and results were compared with those obtained during pregnancy.

This study was approved by the Institutional Review Board of Aichi Medical University, and all participants provided informed consent.

\section{Statistical analysis}

All statistical analyses were performed with Excel Toukei 2012 (SSRI Co., Ltd., Tokyo, Japan). Data are expressed as mean \pm S.D. Unpaired t-test, chi-square test, and one-way analysis of variance were performed for comparisons. The hypothesis was rejected when the probability value was $>0.05$.

\section{Results}

This study retrospectively enrolled a total of 106 pregnant women who showed hypertension by CBP during pregnancy. Mean all-day ABPM determined HDP in 79 women and WCH in 27 women. In HDP, 43 women were classified as PE and 36 as GH according to HDP criteria by JSSHP $[3,8]$.

The number of women who delivered at gestational week $\geq 34$ was smaller for women with PE than for women with GH. FGR was more prevalent among women with PE than those with GH. Serum sFlt-1 concentrations were higher in women with $\mathrm{PE}$ and GH compared to those with $\mathrm{WCH}$.

Hypertension, as assessed by CBP at three months postpartum, was less prevalent in women with PE than in those with $\mathrm{GH}$ (PE, 5/43; GH, 7/36) (Table 1).

\section{Circadian rhythm of BP}

SBP riser were observed in 21 and 15 women with PE and GH, respectively, while DBP riser were observed in 11 and 5 women with $\mathrm{PE}$ and $\mathrm{GH}$, respectively (Table 2). With regard to mild hypertension, as assessed by CBP, SBP between 140-159 $\mathrm{mmHg}$ and/or DBP between 
Citation: Yamamoto T, Suzuki Y, Suzuki H, Matsuura A, Matsushita H, et al. (2018) Changes in Circadian Rhythm due to Possibly Sympathetic Nerve Disorders in Patients with Preeclampsia as Assessed by Ambulatory Blood Pressure Monitoring. J Hypertens (Los Angel) 7: 250. doi: 10.4172/2167-1095.1000250

Page 3 of 6

\begin{tabular}{|c|c|c|c|c|}
\hline & & PE & GH & WCHT \\
\hline Number & & 43 & 36 & 27 \\
\hline Age & year & $33 \pm 5+†$ & $37 \pm 5^{\star *}$ & $33 \pm 5$ \\
\hline Paraous & $\mathrm{PP} / \mathrm{MP}$ & $37 / 6$ & $37 \pm 5^{\star \star}$ & $17 / 10$ \\
\hline BMI & $\mathrm{kg} / \mathrm{m}^{2}$ & $25 \pm 6$ & $26 \pm 6$ & $27 \pm 7$ \\
\hline \multicolumn{5}{|c|}{$\mathrm{CBP}(\mathrm{mmHg})$} \\
\hline Systolic & $\mathrm{mmHg}$ & $158 \pm 15^{\star *}$ & $153 \pm 16^{\star *}$ & $142 \pm 12$ \\
\hline Diastolic & $\mathrm{mmHg}$ & $92 \pm 16^{* *}$ & $95 \pm 14^{* *}$ & $81 \pm 10$ \\
\hline Severe hypertension by CBPף & $(\%)$ & $\begin{array}{c}20 \S \\
(47 \%)\end{array}$ & $\begin{array}{c}10 \\
(28 \%)\end{array}$ & \\
\hline Time of ABPM & gestational weeks & $34 \pm 3$ & $34 \pm 5$ & $22 \pm 9$ \\
\hline SFIt-1 in serum & $\mathrm{pg} / \mathrm{mL}$ & $3215 \pm 65^{\star \star}(n=37)$ & $\begin{array}{c}3190 \pm 185^{*} \\
(n=26)\end{array}$ & $\begin{array}{c}3054 \pm 385 \\
(n=25)\end{array}$ \\
\hline Administration of drugs at ABPM & $(\%)$ & $\begin{array}{c}10 \\
(24 \%)\end{array}$ & $\begin{array}{c}9 \\
(25 \%)\end{array}$ & $\begin{array}{r}0 \\
(0 \%)\end{array}$ \\
\hline \multicolumn{5}{|l|}{ All day BP } \\
\hline Systolic & $\mathrm{mmHg}$ & $150 \pm 14^{* *}$ & $146 \pm 17^{* *}$ & $118 \pm 6$ \\
\hline Diastolic & $\mathrm{mmHg}$ & $93 \pm 8^{* *}$ & $92 \pm 8^{* *}$ & $73 \pm 7$ \\
\hline \multicolumn{5}{|l|}{ Daytime BP (mm Hg) } \\
\hline Systolic & $\mathrm{mmHg}$ & $151 \pm 14^{* *}$ & $148 \pm 16^{\star \star}$ & $122 \pm 7$ \\
\hline Diastolic & $\mathrm{mmHg}$ & $94 \pm 9^{\star *}$ & $92 \pm 8^{*}$ & $76 \pm 8$ \\
\hline \multicolumn{5}{|l|}{ Nighttime BP (mmHg) } \\
\hline Systolic & $\mathrm{mmHg}$ & $149 \pm 17^{\star *}$ & $145 \pm 21^{* *}$ & $109 \pm 7$ \\
\hline Diastolic & $\mathrm{mmHg}$ & $91 \pm 9^{\star \star}$ & $88 \pm 10^{* *}$ & $67 \pm 7$ \\
\hline Delivery at $\geq 34$ gestational weeks & $(\%)$ & $\begin{array}{c}35^{\star *} \dagger \dagger \\
(81 \%)\end{array}$ & $\begin{array}{c}34^{* *} \\
(94 \%)\end{array}$ & $\begin{array}{c}27 \\
(100 \%)\end{array}$ \\
\hline Cesarean section & $(\%)$ & $\begin{array}{l}39^{* *}+\dagger \\
(91 \%)\end{array}$ & $\begin{array}{c}17^{\star *} \\
(47 \%)\end{array}$ & $\begin{array}{c}9 \\
(33 \%)\end{array}$ \\
\hline Fetal growth restriction & $(\%)$ & $\begin{array}{l}25^{\star *}+\dagger \\
(58 \%)\end{array}$ & $\begin{array}{c}7 \\
(13 \%)\end{array}$ & $\begin{array}{c}1 \\
(4)\end{array}$ \\
\hline \multicolumn{5}{|l|}{ Postpartum hypertension by CBP } \\
\hline All & $\mathrm{mmHg}$ & $\begin{array}{c}5 \dagger \\
(12 \%)\end{array}$ & $\begin{array}{c}10 \\
(19 \%)\end{array}$ & $\begin{array}{c}3 \\
(11 \%)\end{array}$ \\
\hline Severe hypertension§ & $\mathrm{mmHg}$ & $\begin{array}{l}4 / 20 \ddagger \\
(20 \%)\end{array}$ & $\begin{array}{c}5 / 10 \ddagger \ddagger \\
(50 \%)\end{array}$ & \\
\hline Mild hypertension§§ & $\mathrm{mmHg}$ & $\begin{array}{l}1 / 23 \\
(3 \%)\end{array}$ & $\begin{array}{c}5 / 26 \\
(19 \%)\end{array}$ & \\
\hline
\end{tabular}

Abbreviations: PE: Preeclampsia; GH: Gestational Hypertension; WCH: White coat hypertension; BMI: Body Mass Index; CBP: Clinic Blood Pressure; PP: Primiparous; MP: Multiporous, Data were expressed as mean \pm s.d.

$\S$, Severe hypertension is SBP $\geq 160 \mathrm{mmHg}$ and/or DBP $\geq 110 \mathrm{mmmHg}$ by CBP during pregnancy or postpartum, $\S \S \mathrm{mild}$ hypertension is SBP at 140 to $159 \mathrm{mmHg}$ and/or

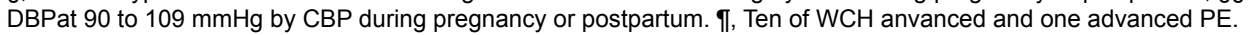

Table 1: BP and clinical data in hypertension disorders in pregnancy patients.

90-109 mmHg was observed more frequently among women with $\mathrm{PE}$ compared to those with GH (PE, 11/23; GH, 4/26).

MESOR, amplitude and \%CV in SBP, DBP and pulse was not different between women with PE and with GH (Table 3).

Mean PR of BP was similar across subjects $(0.19 \pm 0.18 \mathrm{mmHg}$ in women with PE vs. $0.16 \pm 0.14 \mathrm{mmHg}$ in women with GH for SBP, and $0.14 \pm 0.15 \mathrm{mmHg}$ in women with $\mathrm{PE}$ vs. $0.14 \pm 0.12 \mathrm{mmHg}$ in women with GH for DBP).

In women who had circadian rhythm ( $P R \geq 0.16)$, normal maximal SBP at daytime (AT12-18) was detected only in 9/43 women with PE and 9/36 women with GH. In women with $\mathrm{HDP}$ with $\mathrm{PR} \geq 0.16$, AT showed maximal SBP at night-time from 00:00 to 06:00 only in 6/21 women with $\mathrm{PE}$ and $2 / 13$ women with $\mathrm{GH}$, while it showed maximal DBP at night-time in $4 / 18$ women with PE and $1 / 5$ women with GH. Mean PR of pulse was smaller in women with PE than in women with 
Citation: Yamamoto T, Suzuki Y, Suzuki H, Matsuura A, Matsushita H, et al. (2018) Changes in Circadian Rhythm due to Possibly Sympathetic Nerve Disorders in Patients with Preeclampsia as Assessed by Ambulatory Blood Pressure Monitoring. J Hypertens (Los Angel) 7: 250. doi: 10.4172/2167-1095.1000250

Page 4 of 6

\begin{tabular}{|c|c|c|c|c|c|c|c|}
\hline & \multirow[b]{2}{*}{ Number } & \multirow{2}{*}{$\begin{array}{c}\text { Severe/mild } \\
\text { hypertension } \\
\text { by CBP }\end{array}$} & \multirow[b]{2}{*}{ Dipper } & \multirow[b]{2}{*}{ Non-dipper } & \multicolumn{3}{|c|}{ Riser } \\
\hline & & & & & All & $\begin{array}{l}\text { Severe hypertension } \\
\text { mild by CBP }\end{array}$ & Hypertension \\
\hline \multicolumn{8}{|l|}{ I. Systolic } \\
\hline \multicolumn{8}{|l|}{ Preeclampsia } \\
\hline & 43 & $20 / 23$ & $\begin{array}{c}7 \\
(16 \%)\end{array}$ & $\begin{array}{c}15 \\
(35 \%)\end{array}$ & $\begin{array}{c}21 \\
(49 \%)\end{array}$ & $10 / 20$ & $11 / 23+$ \\
\hline \multicolumn{8}{|l|}{$\begin{array}{c}\text { Gestational } \\
\text { hypertension }\end{array}$} \\
\hline & 36 & $10 / 26$ & $\begin{array}{c}6 \\
(17 \%)\end{array}$ & $\begin{array}{c}15 \\
(42 \%)\end{array}$ & $\begin{array}{c}15 \\
(42 \%)\end{array}$ & $6 / 10$ & $4 / 26$ \\
\hline \multicolumn{8}{|l|}{$\begin{array}{c}\text { White coat } \\
\text { hypertension }\end{array}$} \\
\hline & 27 & & $\begin{array}{c}12 \\
(44 \%)\end{array}$ & $\begin{array}{c}15 \\
(56 \%)\end{array}$ & $\begin{array}{c}0 \\
(0 \%)\end{array}$ & & \\
\hline \multicolumn{8}{|l|}{ II. Diastolic } \\
\hline \multicolumn{8}{|l|}{ Preeclampsia } \\
\hline & 43 & $20 / 23$ & $\begin{array}{c}8 \\
(17 \%)\end{array}$ & $\begin{array}{c}25 \\
(56 \%)\end{array}$ & $\begin{array}{c}11 \\
(27 \%)\end{array}$ & $6 / 20$ & $5 / 23$ \\
\hline \multicolumn{8}{|l|}{$\begin{array}{c}\text { Gestational } \\
\text { hypertension }\end{array}$} \\
\hline & 36 & $10 / 26$ & $\begin{array}{c}5 \\
(14 \%)\end{array}$ & $\begin{array}{c}26 \\
(72 \%)\end{array}$ & $\begin{array}{c}5 \\
(14 \%)\end{array}$ & $4 / 10$ & $1 / 26$ \\
\hline \multicolumn{8}{|l|}{$\begin{array}{c}\text { White coat } \\
\text { hypertension }\end{array}$} \\
\hline & 27 & & $\begin{array}{c}12 \\
(44 \%)\end{array}$ & $\begin{array}{c}15 \\
(56 \%)\end{array}$ & $\begin{array}{c}0 \\
(0 \%)\end{array}$ & & \\
\hline \multicolumn{8}{|c|}{ † $\mathrm{P}<0.05$ vs. Gestational hypertension } \\
\hline
\end{tabular}

Table 2: Classification of dipper, non-dipper and riser in HDP patients.

\begin{tabular}{|c|c|c|c|c|c|c|c|c|c|c|c|c|c|}
\hline & \multirow[b]{2}{*}{ Number } & \multirow[b]{2}{*}{$\begin{array}{l}\text { Messor } \\
(\mathrm{mmHg})\end{array}$} & \multirow[b]{2}{*}{$\begin{array}{c}\text { Amplitude } \\
\text { (mmHg) }\end{array}$} & \multirow[b]{2}{*}{$\% \mathrm{CV}$} & \multirow[b]{2}{*}{ PR } & \multicolumn{2}{|c|}{$\begin{array}{l}\text { Circardian } \\
\text { rhythm (-) }\end{array}$} & \multicolumn{6}{|c|}{ Cirdardian rhythm (+) } \\
\hline & & & & & & $P R<0.16$ & $\%$ & $P R \geq 01.6$ & $\%$ & AT0-6 & AT6-12 & AT12-18 & AT18-24 \\
\hline \multicolumn{14}{|l|}{ I. Systolic } \\
\hline Preeclampsia & 43 & $150 \pm 14^{\star *}$ & $8.8 \pm 6.0$ & $10.8 \pm 3.5$ & $\begin{array}{c}0.19 \pm \\
0.18\end{array}$ & $22^{*}$ & 51 & 21 & 49 & 6 & 2 & $9^{* *}$ & 4 \\
\hline $\begin{array}{c}\text { Gestational } \\
\text { hypertension }\end{array}$ & 36 & $145 \pm 17^{* *}$ & $9.5 \pm 6.7$ & $11.8 \pm 5.4$ & $\begin{array}{c}0.16 \pm \\
0.14\end{array}$ & 18 & 58 & 13 & 42 & 2 & 1 & $9^{* *}$ & 3 \\
\hline $\begin{array}{c}\text { White coat } \\
\text { hypertension }\end{array}$ & 27 & $118 \pm 6$ & $9.6 \pm 6.1$ & $11.5 \pm 2.9$ & $\begin{array}{c}0.25 \pm \\
0.13\end{array}$ & 7 & 26 & 17 & 74 & 0 & 0 & 20 & 0 \\
\hline \multicolumn{14}{|l|}{ II. Diastolic } \\
\hline Preeclampsia & 43 & $91 \pm 14^{* *}$ & $5.5 \pm 3.9$ & $11.6 \pm 4.2$ & $\begin{array}{c}0.18 \pm \\
0.17\end{array}$ & 25 & 58 & 18 & 42 & 4 & 2 & $10^{* *}$ & 2 \\
\hline $\begin{array}{c}\text { Gestational } \\
\text { hypertension }\end{array}$ & 36 & $90 \pm 9^{* *}$ & $5.9 \pm 4.3$ & $12.5 \pm 6.8$ & $\begin{array}{c}0.15 \pm \\
0.13\end{array}$ & 21 & 58 & 15 & 42 & 1 & 4 & $8^{* *}$ & 2 \\
\hline $\begin{array}{c}\text { White coat } \\
\text { hypertension }\end{array}$ & 27 & $74 \pm 6$ & $7.0 \pm 3.1$ & $13.5 \pm 2.8$ & $\begin{array}{c}0.19 \pm \\
0.12\end{array}$ & 9 & 33 & 18 & 67 & 0 & 0 & 18 & 0 \\
\hline \multicolumn{14}{|l|}{ III. Pulse } \\
\hline Preeclampsia & 43 & $75 \pm 10^{\star *}$ & $7.3 \pm 4.8$ & $13.5 \pm 5.9$ & $\begin{array}{l}0.27 \pm \\
0.17^{\star} \dagger\end{array}$ & $13^{*} \dagger$ & 30 & $30^{*} \dagger$ & 70 & 0 & 2 & 27 & 1 \\
\hline $\begin{array}{c}\text { Gestational } \\
\text { hypertension }\end{array}$ & 36 & $74 \pm 8^{\star *}$ & $7.5 \pm 4.5$ & $12.6 \pm 5.7$ & $\begin{array}{c}0.32 \pm \\
0.19\end{array}$ & 9 & 25 & 29 & 75 & 0 & 4 & 23 & 0 \\
\hline $\begin{array}{c}\text { White coat } \\
\text { hypertension }\end{array}$ & 27 & $82 \pm 10$ & $9.7 \pm 3.7$ & $14.3 \pm 4.8$ & $\begin{array}{c}0.37 \pm \\
0.18\end{array}$ & 5 & 19 & 22 & 81 & 1 & 1 & 20 & 0 \\
\hline \multicolumn{14}{|c|}{$\begin{array}{c}{ }^{*} \mathrm{P}<0.05 \text { and }{ }^{* *} \mathrm{P}<0.01 \text { vs. White coat hypertension, } \dagger \mathrm{P}<0.05 \text { vs. Gestational hypertension } \\
\% \mathrm{CV} \text { : Percent of Coefficient of Variability; PR: Percent Rhythm }\end{array}$} \\
\hline
\end{tabular}

Table 3: Cirdadian rhythm in HDP.

$\mathrm{GH}$ and $\mathrm{WCH}(\mathrm{PE}, 0.27 \pm 0.7 ; \mathrm{GH}, 0.32 \pm 0.19 ; \mathrm{WCH}, 0.37 \pm 0.18)$. PR $\geq 0.16$ of pulse was also smaller in women with $\mathrm{PE}(28 / 45,62 \%)$ than in women with GH (27/31, 84\%). In women with HDP with $\mathrm{PR} \geq 0.16$, the acrophase of pulse was at 12:00 to 18:00 for 27/30 women with PE and 
Citation: Yamamoto T, Suzuki Y, Suzuki H, Matsuura A, Matsushita H, et al. (2018) Changes in Circadian Rhythm due to Possibly Sympathetic Nerve Disorders in Patients with Preeclampsia as Assessed by Ambulatory Blood Pressure Monitoring. J Hypertens (Los Angel) 7: 250. doi: 10.4172/2167-1095.1000250

Page 5 of 6

25/29 women with GH.

\section{Discussion}

ABPM has been reported to be effective for excluding a diagnosis of $\mathrm{WCH}$ [3]. In the present study, all-day BP, as assessed by $24 \mathrm{~h}-\mathrm{ABPM}$, was able to diagnose HDP as well as WCH. CBP, as well as all-day $\mathrm{BP}$ as assessed by ABPM, were similar in women with PE and GH, although the outcome of pregnancy was more severe in women with PE due to the higher rate of early delivery, cesarean section, and FGR. Furthermore, concentrations of sFlt-1 did not differ between women with $\mathrm{PE}$ and $\mathrm{GH}$, although concentrations were higher in both groups of women compared to women with $\mathrm{WCH}$.

WCH has been reported to be a high risk factor for HDP, including $\mathrm{PE}$ [10]. In the present study, nearly $40 \%$ of women with $\mathrm{WCH}$ developed HDP, in particular, GH. Interestingly, the frequency of persistent hypertension after delivery (postpartum hypertension) was higher in women with $\mathrm{GH}$ than in those with $\mathrm{PE}$, although the outcome of pregnancy was worse in women with $\mathrm{PE}$ than in those with $\mathrm{GH}$ half of the women with $\mathrm{GH}$ who had severe hypertension remained hypertensive postpartum. Recent studies have reported differences in the pathophysiology of PE and GH [3,9]. ABPM could make the differences between these women clearer, not only in terms of clinical manifestations, but also in recovery processes.

\section{Circadian rhythm in women with HDP}

ABPM allows for the assessment of patterns in diurnal BP changes; i.e., it can be used to differentiate between non-dipper, riser, and dipper. The decrease of BP at night-time (sleeping) is reduced in non-dipper, and disappears among riser with HDP. The dipper pattern was not observed in $80 \%$ of HDP cases in this study. However, in over $40 \%$ of HDP cases, SBP was strongly elevated during night-time and exhibited a riser pattern. In mild hypertension cases, this effect was larger in women with PE than in those with GH. Among women with PE, the rate of riser was similar regardless of the severity of hypertension, while among women with $\mathrm{GH}$, the rate was higher in women with mild hypertension.

Sleep or nocturnal hypertension is a common finding in HDP, particularly among women with $\mathrm{PE}$ (PE, 79\%; GH, 45\%) when sleep hypertension is defined as $\mathrm{BP}>117 / 68 \mathrm{mmHg}$ at $26-30$ weeks or $123 / 72$ $\mathrm{mmHg}$ after 30 weeks of gestation [21]. Our results are consistent with this finding. Blunting of the nocturnal drop in BP and the reverse pattern of circadian rhythm of BP both has important clinical implications. Several possibilities have been proposed to explain these phenomena, including:

1) Disturbance in hypothalamic pituitary adrenal periodicity,

2) Disorders of the sympathetic nervous system, and

3) A compensatory mechanism to maintain organ blood flow during sleep in response to ischemia.

Several humoral agents are known to control circulation and BP, such as the renin-angiotensin aldosterone system, free epinephrine, and free norepinephrine. The latter two agents show a temporal sequence of circadian rhythmicity in non-pregnant and normotensive pregnant women, while in women with PE, the circadian rhythmicity of these agents might be blunted.

$\mathrm{BP}$ variability, including $\% \mathrm{CV}$ and $\triangle \mathrm{BP}$, can be used to evaluate outcomes of acute ischemic stroke [12]. MESOR, AT, and \%CV may be useful for evaluating circadian rhythm changes in HDP. According to one report, $\mathrm{PB}$ variation, $\mathrm{MESOR}$, and $\mathrm{AT}$ increased in women with $\mathrm{PE}$ [11], while \%CV has not been assessed, to our knowledge, in women with PE. In the present study, MESOR of BP was higher and MESOR of pulse was lower in both women with PE and GH compared to women with $\mathrm{WCH}$. However, neither amplitude nor \% CV differed significantly across groups.

For BP, the cosine curve represented the best fitted model, and the least squares fit of a cosine curve is frequently used for rhythm detection. $\mathrm{PR}$ is the square of the multiple correlation coefficients between the measured value and the cosine curve best fitted to biological rhythm data. In the present study, there were no differences in the PR of BP among the three groups of women (i.e., $\mathrm{PE}, \mathrm{GH}$, and $\mathrm{WCH}$ ). However, this may have been due to the fact that circadian rhythm using the cosine curve might not be as powerful as the simultaneous fit of all statistically significant components [4].

Patients were also divided into two groups by $\mathrm{PR}$ (i.e., $\mathrm{PR}<0.16$ and $P R \geq 0.16$ ). According to this analysis, more than $50 \%$ of women with HDP were found to lack circadian rhythm. Our findings are consistent with previous reports that $\mathrm{BP}$ variation may be reduced among women with $P E$ [4]. In the group with $P R \geq 0.16$, patients were further classified into four subgroups by acrophase time (AT). Among these groups, normal AT12-18 was observed less frequently in women with PE and GH compared to those with WCH, and AT shifted to the night-time despite the circadian rhythm. In this respect, our results are consistent with a study reporting that AT shifted to the night from the evening [22]. Circadian rhythm of BP disappeared in about $60 \%$ of patients with HDP, and only $20 \%$ of patients with HDP showed normal AT with circadian rhythm.

The circadian rhythm of pulse was abnormal more frequently in women with PE compared to those with GH. This suggests that sympathetic nerve disorders may cause characteristic changes in the circadian rhythm of BP, given that the circadian rhythms of both BP and pulse are abnormal in women with PE.

Baroreflex reportedly is reduced in women with PE $[13,14]$ Indeed, the sympathetic system is abnormal under some pathological conditions. Circadian rhythm is regulated by a circadian rhythm gene, and in the context of PE, this gene may function abnormally in some ways [22].

VEGF reportedly is involved in the adjustment of circadian rhythm. In the present study, sFlt-1 concentrations increased, and this in turn has anti-VEGF receptor effects [23]. In addition to this, PE may also influence circadian rhythm. Another relevant factor is NO. According to a previous report, abnormal NO activity can lead to abnormalities in circadian rhythm [24]. We previously reported the reduced activity of NO-cGMP in the context of vascular function in women with PE $[25,26]$. Thus, PE may impact circadian rhythm not only by affecting $\mathrm{BP}$, but the sympathetic nerve system as well. This underscores the difference between PE and GH in modulating circadian rhythm.

\section{Conclusion}

In conclusion, most women with $\mathrm{PE}$ and $\mathrm{GH}$ showed changes in the circadian rhythm of $\mathrm{BP}$, such as decreases in PR or shifts in peak time, while only women with PE showed changes in pulse. Our findings suggest that the circadian rhythm of BP in women with PE could potentially be disrupted due to sympathetic nerve disorders.

\section{Acknowledgments}

This work was supported in part by a Grant-in-Aid for Scientific Research from 
Citation: Yamamoto T, Suzuki Y, Suzuki H, Matsuura A, Matsushita H, et al. (2018) Changes in Circadian Rhythm due to Possibly Sympathetic Nerve Disorders in Patients with Preeclampsia as Assessed by Ambulatory Blood Pressure Monitoring. J Hypertens (Los Angel) 7: 250. doi: 10.4172/2167-1095.1000250

the Japan Society for the Promotion of Science (26462496).

\section{Conflict of Interest}

None.

\section{References}

1. Imai $Y$, Imaizumi T, Ishimitsu T, Ito M, Ito S, et al. (2014) The Japanese society of hypertension guidelines for the management of hypertension (JSH 2014) Measurement and clinical evaluation of blood pressure. Hypertens Res 37 266-278.

2. O'Brien E, Parati G, Stergiou G, Asmar R, Beilin L, et al. (2013) European Society of Hypertension Working Group on Blood Pressure Monitoring. J Hypertens 9: 1731-1768.

3. Takagi T, Yamasaki M, Nakamoto O, Saito S, Suzuki H, et al. (2015) A review of best practice guide 2015 for care and treatment of hypertension in pregnancy. Hypertens Res Pregnancy 3: 65-103.

4. Hermida RC, Ayala DE, Mojon A, Fernandez JR, Alonso I, et al. (2000) Blood pressure patterns in normal pregnancy, gestational hypertension and preeclampsia. Hypertension 36: 149-158

5. Brown MA, Bowyer L, McHugh L, Davis GK, Mangos GJ, et al. (2001) Twentyfour-hour automated blood pressure monitoring as a predictor of preeclampsia. Am J Obstet Gynecol 185: 618-622.

6. Eguchi K, Ohmaru T, Ohkuchi A, Hirashima C, Takahashi K, et al. (2016) Ambulatory BP monitoring and clinic BP in predicting small-for-gestational-age infants during pregnancy. J Hum Hypertens 30: 62-7.

7. Maggioni C, Cornélissen G, Otsuka K, Halberg F, Consonni D, et al. (2005) Circadian rhythm of maternal blood pressure and fetal growth. Biomed Pharmacother 59: S86-91.

8. Watanabe K, Naruse K, Tanaka K, Metoki H, Suzuki Y (2013) Outline of definition and classification of pregnancy induced hypertension (PIH). Hypertens Res Pregnancy 1: 3-4.

9. Imai $\mathrm{Y}$, Imaizumi $\mathrm{T}$, Ishimitsu $\mathrm{T}$, Ito $\mathrm{M}$, Ito $\mathrm{S}$, et al. (2014) The Japanese society of hypertension guidelines for the management of hypertension (JSH 2014) in women. Hypertens Res 37: 334-338.

10. Brown MA, Mangos G, Davis G, Homer C (2005) The natural history of white coat hypertension during pregnancy. BJOG 112: 601-606.

11. Gupta HP, Singh RK, Singh U, Mehrotra S, Verma NS, et al. (2011) Circadian pattern of blood pressure in normal pregnancy and preeclampsia. J Obstet Gynaecol India 61: 413-417.

12. Shi Z, Li ES, Zhong JS, Yuan JL, Li LR, et al. (2017) Predictive Significance of day-to-day blood pressure variability in acute ischemic stroke for 12-month functional outcomes. Am J Hypertens 30: 524-531.

13. Molino P, Veglio F, Genova GC, Melchio R, Benedetto C, et al. (1999) Baroreflex control of heart rate is impaired in pre-eclampsia. J Hum Hypertens 13: 179-
183.

14. Faber R, Baumert M, Stepan H, Wessel N, Voss A, et al. (2004) Baroreflex sensitivity, heart rate, and blood pressure variability in hypertensive pregnancy disorders. J Hum Hypertens 18: 707-712.

15. Booker CJ, Dodson WC, Kunselman AR, Repke JT, Legro RS (2012) Twentyfour-hour ambulatory blood pressure monitor heart rate: A potential marker for gestational hypertension in at-risk women. Am J Perinatol 29: 339-436

16. Shinozuka N, Okai T, Kohzuma S, Mukubo M, Shih CT, et al. (1987) Fomulas for fetal weight estimation by ultrasound measurements based on neonatal specific gravities and volumes. Am J Obstet Gynecol 157: 1140-1145.

17. Pickering TG, Hall JE, Appel LJ, Falkner BE, Graves J, et al. (2005) Recommendations for blood pressure measurement in humans and experimental animals: part 1: Blood pressure measurement in humans: statement for professionals from the subcommittee of professional and public education of the American Heart Association council on high blood pressure research. Circulation 111: 697-716.

8. Parati G, Stergiou G, O'Brien E, Asmar R, Beilin L, et al. (2014) European Society of Hypertension practice guidelines for ambulatory blood pressure monitoring. J Hypertens 7: 1359-1366.

19. Palatini P, Frigo G, Bertolo O, Roman E, Da Cortà R (1998) Validation of the A\&D TM-2430 device for ambulatory blood pressure monitoring and evaluation of performance according to subjects' characteristics. Blood Press Monit 3 . 255-260.

20. Hermida RC, Ayala DE, Mojon A, Fernandez JR, Alonso I, et al. (2003) Differences in circadian blood pressure variability between healthy and complicated pregnancies. Am J Hypertens 16: 200-208.

21. Brown MA, Davis GK, McHugh L (2001) The prevalence and clinical significance of nocturnal hypertension in pregnancy. J Hypertens 19: 1437-1444.

22. Ditisheim AJ, Dibner C, Phillipe J, Pechere-Bertschi A (2013) Biological rhythms and preeclampsia. Front Endocrinol 4: 47.

23. Levine RJ, Maynard SE, Qian C, Lim KH, England LJ, et al. (2004) Circulating angiogenic factors and the risk of preeclampsia. N Engl J Med 350: 672-683.

24. Hermida RC, Ayala DE, Calvo C, López JE, Mojon A, et al. (2005) Differing administration time-dependent effects of aspirin on blood pressure in dipper, and non-dipper hypertensives. Hypertens 46: 1060-1068.

25. Suzuki Y, Kajikuri J, Suzumori K, Itoh T (2000) Mechanisms underlying the reduced endothelium-dependent relaxation in human omental resistance artery in pre-eclampsia. J Physiol 527: 163-174.

26. Yamamoto T, Suzuki Y, Kojima K, Suzumori K (2005) Reduced flow-mediated vasodilatation is not due to a decrease in production of nitric oxide in preeclampsia. Am J Obstet Gynecol 192: 558-563. 